A Humble Commentary on the Topic of Elders, Honoraria, and Protocol

\author{
Tracy Bear \\ Special Advisor to the Provost, Aboriginal Initiatives \\ $\mathrm{PhD}$ (Candidate) - English and Film Studies, University of Alberta
}

aboriginal policy studies Vol. 2, no. 1, 2012, pp.125-131

This article can be found at:

http://ejournals.library.ualberta.ca/index.php/aps/article/view/17708

ISSN: $1923-3299$

Article DOI: http://dx.doi.org/10.5663/aps.v2i1.17708

aboriginal policy studies is an online, peer-reviewed and multidisciplinary journal that publishes original, scholarly, and policy-relevant research on issues relevant to Métis, non-status Indians and urban Aboriginal people in Canada. For more information, please contact us at apsjournal@ualberta.ca or visit our website at www.ualberta.ca/nativestudies/aps/.

UNIVERSITY OF ALBERTA

FACULTY OF NATIVE STUDIES
Aboriginal Affairs and 


\title{
A Humble Commentary on the Topic of Elders, Honoraria, and Protocol
}

\author{
Tracy Bear \\ Special Advisor to the Provost, Aboriginal Initiatives \\ PhD (Candidate) - English and Film Studies, University of Alberta
}

As many people do, I wear many hats in this life. With respect to writing this commentary, I have a few to acknowledge that are significant. I've been an Indigenous student (Nehiyawe, ${ }^{1}$ specifically) on this campus for almost ten years. I arrived in 2002 with the expectation of staying for one degree; now, in the midst of writing my PhD dissertation, I admit I enjoy campus life. Almost three years ago, in 2009, I was appointed Special Advisor to the Provost Vice-President (Academic) on Aboriginal Initiatives. This wonderful opportunity has allowed me to connect and network with everyone engaged in Aboriginal initiatives at the University of Alberta. I also support the Council on Aboriginal Initiatives (CAI), which was formed in 2008-2009 by the Provost, Dr. Carl Amrhein, and (then) Chancellor Eric Newell. Currently co-chaired by the Provost and "current Chancellor" Linda Hughes, the CAI has created an Aboriginal Strategic document to fortify the University of Alberta's fiveyear strategic plan, Dare to Deliver, through the Elder's Protocol and Guidelines document, and has supported various initiatives and celebratory events on campus.

The University of Alberta resides on Treaty Six territory, and has historically been a central meeting place for many Indigenous peoples like the Cree, Métis, Nakota (Sioux), and Blackfoot. The fertile region around and along the banks of the waterways of the North Saskatchewan River provided an abundance of natural resources, thus creating a natural place for people to trade and gather together. In many ways, our ancestors continue to dwell upon this territory that the University now sits. Aboriginal students and staff integrate and bring to life the stories, knowledge and wisdom of our ancestors within these walls.

More so than ever, universities have been forging ahead and building new relationships and strengthening existing partnerships with Aboriginal peoples, communities, organizations, and individuals. This is certainly the case at the University of Alberta. As more faculties, groups, and organizations across campus access and reach out to Aboriginal communities, the presence of Elders and celebration of ceremony are becoming more and more prevalent. A few highly contested, emotionally charged series of events took place that necessitated the creation of a document to help guide and educate both the university community and the external community of Indigenous people. Not only did we need to define the meaning of what it meant to be an Elder, but we also needed to encapsulate essential principles of reciprocal and respectful protocol between Elders and people seeking Elder guidance. The result is a long-awaited document titled Elder's Protocol and Guidelines (see the foundational documents section of this journal issue for the a copy of this guideline document and its accompanying appendices). The first appendix was authored by Leona Carter, a member of the Council on Aboriginal Initiatives (CAI) ${ }^{2}$ and the Director of the Aboriginal Relations Office for the City of Edmonton. Her extensive background and years

aboriginal policy studies, Vol. 2, no. 1, 2012

125

www.ualberta.ca/nativestudies/aps/

ISSN: 1923-3299 
of experience working with Elders has been foundational to the creation of the guideline. Appendix II is the result of a research project called the Elder's Learning and Resource Council, and Appendix III details the topic of Elder honorariums. Finally, Appendix IV is an addition outlining the protocols surrounding Inuit Elders, and was written by our former Distinguished Scholar in Residence, Susan Aglukark.

Before I begin, understand that the following words are simply my views and my experiences in this realm, given my position as someone involved in the document's production. These comments and opinions do not necessarily reflect the attitudes or perspectives of the University of Alberta, nor are they indicative of any University group or organization. Additionally, I owe a tremendous debt to all of the Elders and/or healers who have encouraged me to continue to seek out knowledge on Indigenous ceremonies, culture, and traditions. They made me understand that wisdom comes in many shapes and forms, and that one must only open one's eyes to see the truth of this. I thank them for telling me (on more than one occasion) that I have two ears and one mouth for a reason. A big hiy hiy also, for their many kindnesses, unconditional friendship, gentle guidance, and willingness to teach me thus far. I hope this commentary does some small justice to all I have learned from them.

I have been told that there have been Elders and community members working and supporting staff and students on the University of Alberta campus as far back as the 1950s, so the concept of garnering knowledge and guidance from Indigenous Elders is not a new one. From personal experience, I accessed Elders from the Aboriginal Student Services Centre (ASSC) when I began my post-secondary education in 2002. I recall an Elder from the nearby reserve, Enoch Cree Nation, visiting one of my Education classes to discuss the challenges surrounding leadership and governance on reserve. The School of Native Studies (now the Faculty of Native Studies) also accessed Elders for blessings and ceremonies for events, ${ }^{3}$ but it wasn't until the fall of 2005 when a formalized, full-time position for an "Elder in Residence" program began at the University, within the walls of the ASSC. This brief document will outline the reasoning and logic behind the research and compilation of the Elder's Protocol and Guidelines document.

The official purpose, quoted directly from the Elder's Protocol and Guidelines document, states that "[g]iven the University's Aboriginal Strategy document statements, policies and the demographics of the province of Alberta, many University employees and units have expressed interest in having Elders come into their classes or having them work on cultural events and other tasks. The purpose of this policy is to establish protocol surrounding:

- The compilation of a list of recognized Elders and areas of expertise;

- Consistency in the offering of honouraria and/or gifts of appreciation;

- The reciprocally respectful treatment of Elders;

- The establishment of an Advisory Committee (ACEPT)" $(2011,6)$.

But the unofficial story is much less bureaucratic, and far more interesting. In 2007, students representing the Aboriginal Student's Council, as well as others from various organizations and faculties, came together to voice their concerns and opinions about Elders. Students were requesting more Elder involvement on campus and were dismayed at 
the conflicting advice regarding Elder roles and responsibilities. As a result, by June 2008, a small qualitative research project was underway, funded by the Faculty of Native Studies, ASSC and the Office of the Provost. The resulting research findings were formalized in October of 2009, in the Elders Leadership and Resource Council-Report to the Provost (ELRC).

Although numerous individuals (including myself) worked on this project, the main team consisted of Jodi Stonehouse (at the time a Faculty of Native Studies undergraduate researcher); Dr. Ellen Bielawski (then Dean, Faculty of Native Studies); Dr. Val Napoleon (then Assistant Professor, Faculty of Native Studies and Faculty of Law); Shana Dion (Director, ASSC); and Karen Pritchard (Administrative Assistant, ASSC). The forty-twopage ELRC document clearly outlined the purpose and mission of this specialized research and introduced the First Nations, Métis, and Inuit Elders who worked or participated in projects at the University of Alberta. The document also summarized what the team had learned from the literature review, the extensive interviews, and the various focus groups and discussion circles. In the end, the working group forwarded three recommendations to the Office of the Provost (Council on Aboriginal Initiatives 2011). While the report's methodology and findings may sound quite straightforward and uncomplicated, nothing could be further from the truth. In fact, connecting with Elders-meeting them and requesting their assistance-proved to be an extremely labour-intensive experience. Even as difficult and time-consuming this preliminary work may be, however, the resulting relationships and deeply meaningful friendships have proven to be invaluable.

The ELRC project worked diligently on building relationships with the Elders that were to be interviewed, and this aspect of the project was critical to creating trust and respect. The ELRC project referred to this as the "snowball method." Using a "snowball sample" method, student researchers engaged in numerous discussions to build trust and understanding about the project, then they began the process of asking for referrals to Elders and Elder helpers. ${ }^{4}$ Once a name was provided, it was up to the student researchers to begin to build a relationship with that Elder. As the ELRC project demonstrates, this process required time. Student researchers visited with Elders, had tea, went for walks, and even journeyed along trap lines with them. After a respectable amount of time, the student researcher would then offer a small gift and tobacco, and formally ask the Elder to participate in interview(s). The Elders were also asked to participate in an Elder's Gathering, where they were presented with a first draft of the ELRC. Participants also had an opportunity to discuss the critical questions raised in the draft report.

The results of the ELRC demonstrate a healthy diversity of opinions regarding what it means to be an "Elder." As happened in my own experience with some Elders, the questioning of cultural authenticity became a heated topic of discussion. Conflict does not have to be destructive, however, and in the case of the ELRC, the facilitators were able to manage respectful discussions on these and similarly sensitive topics. The ELRC report quotes Verna St. Denis, who examined the ideas of cultural authenticity and its potential detrimental effects on Indigenous communities and organizations. She said, "Authentic cultural identity has become high currency. Some of the markers of cultural authenticity include speaking one's Aboriginal language, having knowledge of and participating in a myriad of spiritual practices, and having knowledge of traditional stories and other 
practices of the past" (St. Denis 2004, 36). Remaining fixed on the idea that there is only one culturally authentic "right" way of being Indigenous will prevent the realization of selfdetermination. The ELRC group of students discussed the problematic concept of a "core Native identity" and how contemporary society must let go of such limiting notions.

The focus group discussions and the personal interviews that the ELRC facilitated in trying to define the meaning of an "Elder" brought many critical issues to the forefront. One of these issues includes the difficult topic of money for Elder services (advice, knowledge, wisdom, experience, medicines, etc). Often a hushed subject, cash is now a widely accepted currency with Elders. Depending on the decade, Elder services have been, and in some areas continue to be, exchanged for a variety of items ranging from (but certainly not limited to) horses, guns, game, food, furs, vehicles, laptops, and many other household items. But, more often than not, today's Elders' services are exchanged for a cash amount. The confusion arises when a large organization such as the University of Alberta, which houses a plethora of diverse organizational spaces, including faculties, departments, student groups, unions and various organizations, attempts to engage Elders without a clear, mutual understanding of expectations. Many Elders have told me that you are expected to "give what you can" for Elder services, and that the "payment" should represent the value that you place upon the service rendered. For example, if you were to request the services of a well-known healer to restore a loved one to good health, the compensation would not only represent the value of your loved one's well-being, but would also be balanced with what you could afford. In one case, I personally saw a family gift a brand-new truck as thanks and compensation for the healing of their son.

Indigenous communities are often smaller populations where the work and history of community Elders and/or healers are well known and respected. They are related through complex networks of relationships and kinship. Their reputations and/or skills are recognized and accepted by the community to which they belong and, as such, they carry a responsibility and accountability to the community. Is it possible to transfer these types of reciprocal understandings into the generally larger and less integrated space of a university? This is a question that continues to circulate. To quote an Elder from ELRC, "Cause that's such an intimate setting in your community. And when I think of the students at the University of Alberta and Elders ... they don't really know of anything about people ... They're kind of strangers. So how do you mitigate that? How do we, by having more Elders' involved, or how do you think?" (Fox, interview, qtd. in Council on Aboriginal Initiatives 2011, 39). Indeed, our campus community is connecting with Elders as never before, and I've witnessed some of these growing pains firsthand. "Pay what you can" is the mantra I hear most often, but the University is a large organization and the various groups-whether a large faculty or small student council-often have widely differing budgets. For example, a large faculty and a humble student group both request the services of an Elder. If we go upon the "pay what you can" formula, the student group may possibly host a modest lunch and gift the Elder with a small gift of appreciation. The larger faculty, on the other hand, could conceivably pay a larger honorarium. Obviously the University does not function like the smaller setting of an Indigenous community, as we have over 35,000 students and 15,000 staff, but bad feelings and false impressions have come about when various groups on campus have given vastly different honorariums. Groups with larger budgets have 
inadvertently raised the standard for honorariums and gifts as they have taken to heart the virtue of "pay what you can." The fact that not every group on campus can afford to be as generous, combined with the prevalent misconception that the University functions as one single entity, often results in misunderstandings.

How can this be mitigated? I think the methodology of the ELRC could lead by example. Building relationships between University personnel and the Elders that they hope to engage is an essential part of the process. However, to answer the question at hand: what constitutes appropriate monetary compensation for services rendered by an Elder? Once again, before beginning a discussion about this specific topic, it is important to note the difficulty in applying one standard policy, process, or monetary amount when working with Elders. From the beginning, the people who have worked on the various parts of this document have vociferously asserted this conviction. With much apprehension and trepidation, Appendix III was added to the entire document, and for this precious information we must thank the Aboriginal Student Services Centre (ASSC). They have shared with the CAI, and thus, the University at large, their cash reimbursement policy. The printed version of the Elder's Protocol Guideline document will not include specific amounts for cash honorariums, although our website www.aboriginal.ualberta.ca will make these suggested dollar amounts available. Wisely, the CAI has considered that a printed document with a set of honorarium monetary amounts could quickly go out of date, due to the rising costs of living. Not attaching a fixed dollar amount to the printed version ensures that the Elder's Protocol and Guidelines document will enjoy a longer life on campus.

Our campus has also struggled with the method in which to give monetary compensation. The recent tightening enforcement of "no cash" University policies has seen an increase in the willingness of external auditors to penalize universities who continue to hand out cash instead of cheques. Widely publicized violations often come with significant penalties. Consequently, researchers, staff, and students alike began to offer monetary compensation in the form of cheques to Elders for services rendered. Cheques are the obvious and easy answer, one might assume-if you knew the name of the person, their social insurance number, date of birth, and address - all three to four weeks in advance.

However, there are several occasions where a cheque is not practical at all. Take, for instance, a round dance. These events need hand-drummers to attend the event. No handdrummers means no dancing, which means no round dance. Usually the invitation is quite informal and is accomplished by the event coordinators attending other round dances and asking the hand-drummers to come and drum at their future event. Depending on the timing, location, and popularity, you may have ten to forty hand-drummers show up at your event. Each hand-drummer receives a honorarium for their time and talent. Obviously, it is impossible to predict who will attend, as no formal RSVP is required. Other events, such as Pipe ceremonies, are similarly unpredictable regarding attendance numbers. A Traditional Feast excludes no one, and the participants are unforeseeable. The head Elder is always a known variable, but sometimes the four attending Elders that assist in prayers during the ceremony are not. The four assisting Elders are often given a gift of a blanket and an honorarium. Experience has taught me to trust the leadership and knowledge of the head Elder, who will choose the right Elders to help with the ceremony on that day. Early on in my position, I foolishly prepared cheques for specific assisting Elders, not understanding that it isn't until the moment we are all seated in the circle and about to begin the ceremony that the head Elder will choose his/her helpers. 
Recently, I had an epiphany while giving out ten-dollar gift cards to our young helpers who assisted the Elders at one of our Traditional Feasts. I approached an Elder with whom I had worked with in the past, and asked if it would be appropriate to give out honorariums not in cash or cheque, but in the form of a VISA or M/C gift-card. In this way, giving an honorarium could be more fluid, as some situations require. Hence, Appendix III suggests that honorariums could be given in the form of a VISA or M/C gift-card in the appropriate amount. As the document suggests, it is crucial to discuss these changes with the potential Elder(s) prior to offering tobacco and asking for services.

Not all my experiences with Elders have been entirely positive; I've been at the receiving end of some pretty harsh teachings, but I have learned something from each experience. Since then, I've come to understand that Elders come in many shapes and forms, have their areas of expertise, and come from diverse backgrounds. I've learned that anyone seeking services and assistance from Elders must reflect on the meaning of Elders and strive to build and maintain a balanced, respectful, reciprocal relationship with the Elders they eventually work with. The finished Elder's Protocol Guideline document is the product of endless discussion and candid reflection from many voices with years of experience. When I consider the blunders I have made in the past, it surely would have been a pleasure to come across upon a document such as this to guide me. Recognizing that we all come from assorted backgrounds that have a range of varied experiences with Elders, it is our hope that the Elder's Protocol \& Guideline document will provide advice and guidance. It is not our intention to create a policy and procedure document, but to assist university employees and units to engage with Elders in a reciprocally respectful manner. 


\section{Notes}

1. Nehiyawe meaning a Cree person.

2. The Council on Aboriginal Initiatives is a council co-chaired by the Provost and VicePresident Academic (Research) and the Chancellor. The membership includes members of the Senate, Deans, faculty members, Aboriginal student group representatives and other university staff who work in some capacity with Indigenous initiatives and organizations on campus. The CAI was initially formed in 2009 and has contributed to the University five-year strategic plan, Dare to Deliver, with a specific Aboriginal Strategic document.

3. "Elder in Residence" programs existed at Native Studies, but this was one day per month and funding was sporadic (R. Price, personal communication, qtd. in Council on Aboriginal Initiatives 2011).

4. As I understand it, there are many variations of Elder's helpers. Young apprentice Elders are often called oskapews, and are Elders-in-training. Other helpers could be seen as caregivers who make sure the Elders are comfortable. Helpers may also be chauffeurs, translators, or go-betweens.

\section{Bibliography}

Aboriginal Peoples Network Website. 2011. www.aboriginal.ualberta.ca

Council on Aboriginal Initiatives. 2011. Elder's Protocol \& Guideline. Council on Aboriginal Initiatives, University of Alberta.

St. Denis, V. 2004. "Real Indians: Cultural Revitalizaiton and Fundamentalisma in Aboriginal Education." In Contesting Fundamentalisms, ed. C. Schick, J. Jaffe, and A. M. Watkinson, 35-47. Halifax: Fernwood. 